\title{
STUDY OF THE INCIPIENT MOTION OF BED PARTICLES FOR GRAVEL BED CHANNELS
}

\author{
Kassem Salah Abd EL-Wahab E]- Alfy \\ Assistant Prof., Dept. of Irrigation and Hydraulics, \\ Faculty of Engineering, Mansoura Univ., Egypt.
}

\begin{abstract}
For rivers in flood, the shear stress at the top of the stationary gravel bed can set up a sheared layer of contact-load (bed-load). As is well known, movement of solid particles does not initiate until the shear stress exceeds some critical value $\left(\tau_{c}\right)$. The main objective of this research is the laboratory prediction of the conditions at which the incipient motion occurs in the gravel bed channels through fifteen grading of gravel bed. The laboratory critical shear stress for every bed grading is computed and compared with that resulted from formulae used in calculating the critical shear stress on channel bed. The experimental analysis is used to obtain the relations describing the boundary of the initiation of motion of the gravel bed particles. Also the flow velocity adjacent to bed and the mean flow velocity are measured at the critical conditions (case of incipient motion). The influence of the value of the downward angle of the bed on the critical shear stress is also examined.
\end{abstract}

From the laboratory experiments, it was concluded that the values of the critical shear stress are similar to the values from the existing formulae, especially Shields diagram, and Shulits and Hill formula. From the measurements of the bed velocity at the incipient motion conditions, a relationship between the dimensionless critical bed velocity $\left(\mathrm{V}_{\mathrm{bo}} / \mathrm{V}_{\mathrm{mc}}\right)$ and the ratio (Re/Fnd) is predicted. It is also noticed that there is an inverse proportionality between the downward bed angle and the critical shear stress required to initiate motion of the gravel bed.

KEYWORDS: shear stress; incipient motion; critical conditions; bed particles.

Manuscript received from Dr. Kassem Salah on : 28/3/2000

Accepted on : 18/4/2000

Engineering Research Bulletin, Vol 23, No 3, 2000 Minufiya University, Faculty of

Engineering, Shebien EJ-Kom, Egypt, ISSN 1110-1180 


\section{INTRODUCTION}

The hydraulic roughness of gravel bed arises from both a skin friction of bed surface and irregularities of the bed surface and grains transported in the body of the flow (form roughness). In 1989, Griffith [7] stated that in natural channels, form resistance is presented when the bed surface starts motion (but not necessarily deformed by accompanying sediment transport) or when the bed is rigid and covered with inert bed forms. In $1935 \mathrm{Kramer}$ [10] concluded that it is difficult to decide that particles motion has begun, he also defined three types of bed particles motion, (1)- weak movement (few particles are in motion -can be counted) (2)-medium movement, the grains of mean diameter begin to move (3)-general movement, all the mixture is in motion all the time.

Many researchers such as Schoklitch [13], Shields [14], White [18], Tison [16], Simons and Richardson [15], Vizgo [17] had attempted to solve the problem of the initiation of motion.

\section{THEORETICAL APPROACH}

There are many definitions for the critical shear stress, Chien [3] concluded that the critical shear stress depends only on $d_{50}$ of the bed material. The bed grains under motion lies under the forces of flowing water, and the forces that resist motion. The resisting forces depend mainly on the properties of bed material. The forces acting on a particle in a flowing fluid are, the submerged weight, and the drag force. At the initiation of motion the grains are still resting on bed, and the lift force can be neglected.

a- The submerged weight of the grain as stated by White [18]

$$
F_{g}=c_{1}\left(\gamma_{s}-\gamma_{w}\right) D_{s}^{3}
$$

in which

$\mathrm{F}_{\mathrm{g}} \quad$ the submerged weight of the grain

$c_{1} \quad$ form coefficient $=\Pi / 6$ for spherical particles

$\gamma_{s} \quad$ specific weight of particles

$\gamma_{w}$ specific weight of water

$D_{s} \quad$ characteristics diameter of particle

b- The drag force affects the grain in laminar flow as stated by White [18];

$$
F_{d}=\tau_{0} c_{2} D_{s}^{2}
$$


in which

$F_{d} \quad$ drag force

$\tau_{0} \quad$ bed shear stress

$c_{2}$ form coefficient defining the effective surface area

If the moment is taken about the point of support of the particle rested on an inclined bed with angle $\phi[6]$, then

$$
c_{1}\left(\gamma_{s}-\gamma_{w}\right) D_{s}^{3} a_{1} \sin (\theta-\phi)=c_{2} \tau_{0} D_{s}^{2} a_{2} \cos \theta
$$

at the critical condition (initiation of motion ) $\tau_{0}=\tau_{c}$ then,

$$
\begin{gathered}
c_{1}\left(\gamma_{s}-\gamma_{w}\right) D_{s}^{3} a_{1} \sin (\theta-\phi)=c_{2} \tau_{c} D_{s}^{2} a_{2} \cos \theta \\
c_{1}\left(\gamma_{s}-\gamma_{w}\right) D_{s}^{3} a_{1}(\sin \theta \cos \phi-\cos \theta \sin \phi)=c_{2} \tau_{c} D_{s}^{2} a_{2} \cos \theta \\
\tau_{c}=\frac{c_{1} a_{1}}{c_{2} a_{2}}\left(\gamma_{s}-\gamma_{w}\right) D_{s} \frac{(\sin \theta \cos \phi-\cos \theta \sin \phi)}{\cos \theta}
\end{gathered}
$$

for the horizontal bed $\phi=$ zero

$$
\tau_{c}=\frac{c_{1} a_{1}}{c_{2} a_{2}}\left(\gamma_{s}-\gamma_{w}\right) D_{s} \tan \theta
$$

where

$a_{1}, a_{2}$ distance between the point of support and center of gravity and furthest point of the particles

$\theta \quad$ angle of repose of submerged sediment

$\phi \quad$ angle of slope of the bed

In 1940, White [18] studied the equilibrium of the particle in laminar flow and defined the critical shear stress as:

$$
\tau_{c}=0.18\left(\gamma_{s}-\gamma_{w^{\prime}}\right) D_{s} \tan \theta
$$

equating eqn. (7) by eqn. (8)

$$
\tau_{c}=0.18\left(\gamma_{s}-\gamma_{w}\right) D_{s} \tan \theta=\tau_{c}=\frac{c_{1} a_{1}}{c_{2} a_{2}}\left(\gamma_{s}-\gamma_{w}\right) D_{s} \tan \theta
$$


then . $\quad \frac{c_{1} a_{1}}{c_{2} a_{2}}=0.18$

for fully turbulent flow [6], $a_{1}=a_{2}$

then

$\frac{\tau_{c}}{\left(\gamma_{s}-\gamma_{w}\right) D_{s}}=K \tan \theta$

where $K=\frac{c_{1}}{c_{2}}$

the parameter $\frac{\tau_{c}}{\left(\gamma_{s}-\gamma_{w}\right) D_{s}}$ is the ratio of the drag force to the gravitational force. This dimensionless number is a type of Froude number, which is related to the grain size and the shear velocity.

In 1969 Cheng [2] gave the following relation that controls or defines the incipient motion of the particle

$$
\frac{\rho U_{{ }_{c}}^{2}}{\left(\gamma_{s}-\gamma_{w}\right) D_{s}}=2.0\left(\frac{D_{s}}{y}\right)^{2 / 3}
$$

where; $U_{*_{c}}$ is the critical shear velocity

Many researches have been published during the last thirty years. Ippen and Verma [9] and Bogardi [1] had studied the initiation of motion. In 1936, Shields [14] constructed (on his diagram) a relation between the boundary Reynolds number $\left(\frac{D_{s}}{v} \sqrt{0.1\left(\frac{y_{s}}{\gamma}-1\right) g D_{s}}\right)$ and the dimensionless shear stress $\left(\frac{\tau_{c}}{\left(\gamma_{s}-\gamma\right) D_{s}}\right)$. He concluded that for the boundary Reynolds number more than 1000 , the value of the dimensionless shear stress is considered to be 0.06 . Meyer-Peter and Muller [11] suggested a value of 0.047 instead of 0.06 . Shulits and Hill [12] treated the problem in another way, they divided the problem into four segments and provided an equation for each segment as follow;

$$
\begin{array}{ll}
\tau_{c}=0.0215 D_{s}^{0.25} & \text { for } 0.0003<D_{s}<0.0009 \mathrm{ft} \\
\tau_{c}=0.0315 D_{s}^{0.633} & \text { for } 0.0009<D_{s}<0.0018 \mathrm{ft} \\
\tau_{c}=16.8 D_{s}^{1.262} & \text { for } 0.0018<D_{s}<0.022 \mathrm{ft} \\
\tau_{c}=1.18 D_{s} & \text { for } D_{s}>0.022 \mathrm{ft}
\end{array}
$$




\section{LABORATORY WORK}

The expeximents are carried out in the laboratory of the Irrigation and Hydraulics, Civil Engineering Department, Menoufia University. The ." experimental set-up consists basically of a tilting recirculating glassed flume of rectangular cross-section, with effective length of $14.0 \mathrm{~m} ., 0.60 \mathrm{~m}$. width and $0.60 \mathrm{~m}$. depth. The flume is provided by an upstream tank of $1.50 \mathrm{~m}, \mathrm{x} 0.80 \mathrm{~m}$. $\mathrm{x} 1.50 \mathrm{~m}$. A downstream tail gate is used to control the flow depth. The flume is fed with water through two centrifugal pumps each of which discharges 60 liter/sec. The levels are measured by Vernier point gauge and the flow rates are controlled with valves and measured with the digital current meter. Precautions are considered at the upstream tank to reduce water level disturbance. The flow velocity is measured with the digital current meter.

\section{EXPERIMENTS PROCEDURE}

The experiments are carried out using different grading of the gravel bed with $d_{50}$ of $3.0,5.0,6.0,7.5,10.5,13.0,17.3,19.2,22.0,24.8,27.0,30.1,33.0$, 37.6 , and $39.0 \mathrm{~mm}$ as a result of sieve analysis of the different samples. A discharge of 82.0 liter/sec is used. The downstream Jack; which the flume is supported on, is lowered on steps, each step is $15 \mathrm{~cm}$ in the cases of bed $d_{50}$ equals $3.0,6.0,10.5,19.2,24.8,30.1$, and $39 \mathrm{~mm}$ to produce a downward angle $(\phi)$ of $1.5^{\circ}, 3.0^{\circ}, 4.5^{\circ}, 6.0^{\circ}$, respectively. The following procedure is followed for each of the performed runs:

1- The flume is adjusted horizontally, i.e. $(\phi)$ equals zero.

2- A certain discharge is regulated using the calibrated valve on the intake pipeline, and the exact discharge is measured by using both the flowmeter fixed on the delivery pipe and the calibrated sharp crested weir on the recirculating brick flume, which is found to be 82.0 liter/sec.

3- The bed particles under study is leveled horizontally and compacted carefully away from the upstream tank by $4.0 \mathrm{~m}$. on a reach of $3.0 \mathrm{~m}$. length with thickness of $10.0 \mathrm{~cm}$.

4- The tail gate is closed, and the flume is filled with water before the pump is switched on.

5- The pump is switched on.

6- The end tail gate is opened very slowly by another person in the same field, while the bed particles are observed throughout the very clear glassed sides of the flume by the researcher.

7. When more than $50 \%$ of the particles initiate motion, the opening of the tail gate is stopped. 
8- Both the water level and mean velocity are measured at both the beginning and the end of the studied reach to determine the slope of the energy line.

9- The flow velocity is measured at the bed ( $3 \mathrm{~mm}$ above the bed) at the middle of the studied reach using the digital pitot tube.

10-The mean flow velocity (at 0.6 of flow depth) is measured at the middle of the studied reach using the digital pitot tube.

11-At the end of the measurements the pump is switched off.

12-The critical shear stress on bed $\tau_{c}$ (at the incipient motion of bed particles) is computed as stated by Zedain [19] as $\tau_{c}=0.97 \gamma_{w} \mathrm{yS}$, where $\mathrm{y}$ is the flow depth on the middle of the studied reach, and $S=S_{f}\left(S_{f}\right.$ is the energy line slope).

13-The gravel bed material on the studied reach is replaced by another grading.

14- Steps (2 to 12) are repeated for each value of the bed grading.

The effect of the downward angle of the bed on the incipient motion is studied for the grading of $3.0,6.0,10.5,19.2,24.8,30.1$, and $39 \mathrm{~mm}$ through the following steps:

1- The flume is kept horizontally.

2- The bed is leveled and compacted carefully on a horizontal bed.

3- The flume is inclined by lowering the downstream jack by $15 \mathrm{~cm}$.

4- The downstream tail gate is closed and the flume is filled with water.

5- The pump is switched on.

6- The tail gate is opened until the particles initiate motion.

7- The aforementioned parameters are measured as the above description.

8- The pump is switched off.

9- Steps (2-8) are repeated for another jack step $(15 \mathrm{~cm})$.

10-The process is repeated until the jack lowering reaches $60 \mathrm{~cm}$ to produce different values of downward angle of $1.5^{\circ}, 3.0^{\circ}, 4.5^{\circ}, 6.0^{\circ}$, respectively.

\section{RESULTS AND ANALYSIS}

The experimental results of the present investigation are graphically represented. The critical shear stress values are plotted against different values of bed material median diameter $d_{50}$, boundary Reynolds number, and densimetric Froude number. Also, a comparison among these results and the other analytical results is carried out.

On Fig. 1, the dimensionless critical shear stress is plotted against the critical boundary Reynolds number. From the experimental data illustrated on Fig. 1. it is shown that the correlation between the dimensionless critical shear stress with the boundary Reynolds number may be approximated by the following simple expression. 


$$
F_{*}=\frac{\tau_{c}}{\left(\gamma_{s}-\gamma\right) d_{s}}=0.0215 R_{*}^{0.15}
$$

The comparison between the experimental results and the corresponding ones resulted from Shields diagram shows that there is a small difference, which is not more than $8.5 \%$. This difference can be referred to the difference in determination the state of the initiation of motion.

Fig. 2, shows the comparison between the dimensionless critical shear stress for the different gravel bed grading results from the laboratory measurements and those predicted by Gessler [6]. It is found that the difference is small in small bed diameter and increases in big one, which ranges between $10.9 \%$ and $18 \%$. A part of this difference can be referred to the lack of accuracy in the measurement equipements, the determination of the initiation of motion and to the difference in some constant parameters in the dimensionless terms used in Gessler relation.

Fig. 3, shows a relation between the critical shear stress versus bed $d_{50}$ for both the experimental results and the relation derived by Shulits and Hill [12] in feet units system. Both the experimental results and Shulits relation follow the same trend, but there is a small difference between the two relations, which ranges from $3 \%$ at small diameters and $18.3 \%$ at large bed diameters. From the experimental results the critical shear stress can be represented by the following relation;

$$
\tau_{c}=4.67 d_{s}^{0.96} \quad \text { (in feet units) }
$$

The comparison of the pervious analytical results (after Chien, 1954 [3]) with that resulted from the experiments are shown in Fig. 4. The solid lines indicate the range of the theoretical values of the critical shear stress versus $d_{50}$, while the dotted line, represents the data from the flume experiments for the same range of bed material grading. From Fig. 4, it is found that the laboratory critical shear stress lies within the range of these analytical results.

To study the critical flow velocity adjacent to bed (at the incipient motion of bed particles), both the mean velocity of the flow and velocity adjacent to bed are measured using the digital pitot tube at the middle of the study reach. Fig. 5. shows the relation between the dimensionless critical bed velocity on the gravel bed channel in range of $3.0 \mathrm{~mm}$ to $39.0 \mathrm{~mm}$; versus the ratio between Reynolds number and densimetric Froude number $\left(R_{e} / F_{N d}\right)$. This relation can be summarized in the following relation; 


$$
\frac{V_{b c}}{V_{m c}}=0.294\left(\frac{R_{c}}{F_{N d}}\right)^{0.0589}
$$

The effect of the downward angle on the critical shear stress value is also studied on the cases of bed grading of $d_{50}$ equals to $3.0,6.0,10.5,19.2,24.8$, 30.1 , and $39 \mathrm{~mm}$. for the downward angle of $1.5^{\circ}, 3.0^{\circ}, 4.5^{\circ}, 6.0^{\circ}$. From Fig. 6 , it is found that as the downward bed angle increases the bed particles initiate motion at a flatter water surface, which means that the value of shear stress required to initiate motion of the bed particles decreases. This can be explained due to the fact that the increase in downward angle increases the weight component in direction of flow, which increases the forces causing motion.

\section{CONCLUSIONS}

The theory and analysis of the experimental data led to the following conclusions:-

1- From the laboratory study, it can be concluded that the critical shear stress resulted from the laboratory experiments are consistent with the existing formulae especially with that resulting from Shields diagram and Shulits and Hill formula for the same bed conditions.

2- From the laboratory study, a relationship between the dimensionless critical bed velocity and the ratio $\left(\mathrm{R}_{\mathrm{e}} / \mathrm{F}_{\mathrm{Nd}}\right)$ is predicted.

3- It is also noticed that there is an inverse proportionality between the downward bed angle and the critical shear stress required to initiate motion of bed particles.

4- According to the results of the present study, two relationships are given, which can be considered as a helpful tool in determining the critical shear stress, which causes the incipient motion of gravel bed particles. They may be listed in the following manner:

a- $F_{*}=\frac{\tau_{\mathrm{c}}}{\left(\gamma_{\mathrm{s}}-\gamma\right) \mathrm{d}_{\mathrm{s}}}=0.0215 \mathrm{R}^{0.15}$

b- $\tau_{c}=4.67 d_{s}^{0.96}$

5- Using the dimensionless variables, the velocity near bed at the incipient motion can be calculated from the following relation,

$$
\frac{V_{l k}}{V_{m c}}=0.294\left(\frac{R_{c}}{F_{N l}}\right)^{0.0589}
$$

\section{REFERENCES}

1- Bogardi, J. L., 1965, "Eurpean Concepts of Sediment Transportation". J. of Hydraulics Division. ASCE. Vol. 91, No. Hy 1 
2- Cheng, D. H., 1969, "Incipient Motion of Large Roughness Elements in Turbulent Open Channel Flow", Dissertation, Utah State University.

3- Chien, N., 1954, "The Present Status of Research on Sediment Transport", Proceedings, ASCE, Vol. 80.

4- Fidelia. N. Nnadi and Kenneth C. Wilson (1992), "Motion of Contact-Load Particles at High Shear Stress", ASCE, Vol. 118, No. 12.

5- Gessler, J. (1965), "The beginning of bed load movement of mixtures investigated as natural armoring in channels", W.M. Keck Lab. of Hydraulics and Water Resources, Calif. Inst. Techn., Pasaden.

6- Gessler, J. (1971), "Beginning and ceasing of sediment motion", River Mechanics, edited by H. W. Shen, Chapter 7, Fort Collins, Colorado.

7- George A. Griffiths (1989), "Form Resistance in Gravel Channels with Mobile Beds", ASCE, Vol. 115, No. 3.

8- Hughes, W.C., and Flack, J. E., (1984), "Hydraulic Jump Properties over a Rough Bed", Journal of Hydraulic Engineering, Vol. 110, No. 12, Dec., ASCE, ISSN, paper No. 19347, pp. 1755-1772.

9- Ippen, A. T., and Verma, R. P., 1953, "The Motion of Discrete Particles along the Bed of a Turbulent Stream", Proceedings, $5^{\text {th }}$ Congress of IAHR, Minneapolis.

10- Kramer, H. (1935), "Sand mixture and sand movement in fluvial models", Transactions, ASCE, Vol. 100, pp. 798-878.

11- Meyer-Peter, E., and Muller, R. (1948), "Formulas for bed-load transport", proceedings, III Cong. IAHR, Stockholm.

12- Schulits, S., and Hill, R.D. (1968), "Bed Load formulas, Part A. A selection of bed load formulas", The Pennsylvania state University, College of Eng., University park, Pennsylvania.

13- Schoklitsch, A., 1914, "Uber Schleppkraft und Geschiebewegung," Engelmann, Leipzig (in German)

14- Shields, A., 1936, "Anwendung der Aehnlichkeitsmechanik und Turbulenz Forschung auf die Geschiebewegung", Mitteilung Preussischen Versuchanstalt Wasser, Erd, Schiffbau, Berlin, No. 26 (in German).

15- Simons, D. B., and Richardson, E. V., 1966, "Resistance to Flow in Alluvial Channels", USGS Professional Paper 422-J.

16- Tison, L. J., 1953, "Recherché sure la Tension Limit d'Entrainement des Materiaux Constitutifs du Lit", IAHR, Sth Congress, Minneapolis.

17- Vizgo, M.C., (1963), Institute of Water Problems and Hydraulics, Academy of science, Technical Bulletin No. 12, Tashkent.

18- White, C. H. (1940), "Equilibrium of grains on the bed of a stream", Proc. Roy. Soc. London, Vol. 174A

19- Zidan Abdel. R., (1984), "Lecture Notes on Hydraulics", Faculty of Eng.. El-Mansoura University. 


\section{NOTATION}

The following symbols are used in this paper:

$a_{1}, a_{2}$ distance between the point of support and center of gravity and furthest point of the particles

$c_{1} \quad$ form coefficient $=\Pi / 6$ for spherical particles

$c_{2} \quad$ form coefficient defining the effective surface area

$d_{3}$ median diameter of bed particles $=d_{50}$

$D_{s} \quad$ characteristics diameter of particle

$F_{d}$. drag force

$F_{g}$ the submerged weight of the grain

$F_{N d}$ densimtric Froude Number

$F_{*} \quad$ dimensionless critical shear $=$

$$
\tau_{c} /\left(\gamma_{s}-\gamma_{w}\right) D_{s}
$$

g gravitational acceleration

$\mathrm{S}$ bed slope

R* Renyolds number

$R_{*} \quad$ boundary Reynolds Number $=\frac{D_{s}}{v} \sqrt{0.1\left(\frac{\gamma_{s}}{\gamma}-1\right) g D_{s}}$

y water depth

$V_{b c} \quad$ flow velocity adjacent bed at critical conditions

$V_{m c} \quad$ mean flow velocity at critical conditions

$\theta$ angle of repose of submerged sediment

$\phi \quad$ angle of slope of the bed

$\gamma_{s}$ specific weight of particles

$\gamma_{\mathfrak{w}^{\prime}} \quad$ specific weight of water

$\tau_{0} \quad$ bed shear stress

$\tau_{c} \quad$ critical shear stress

$U$ *c critical shear velocity 


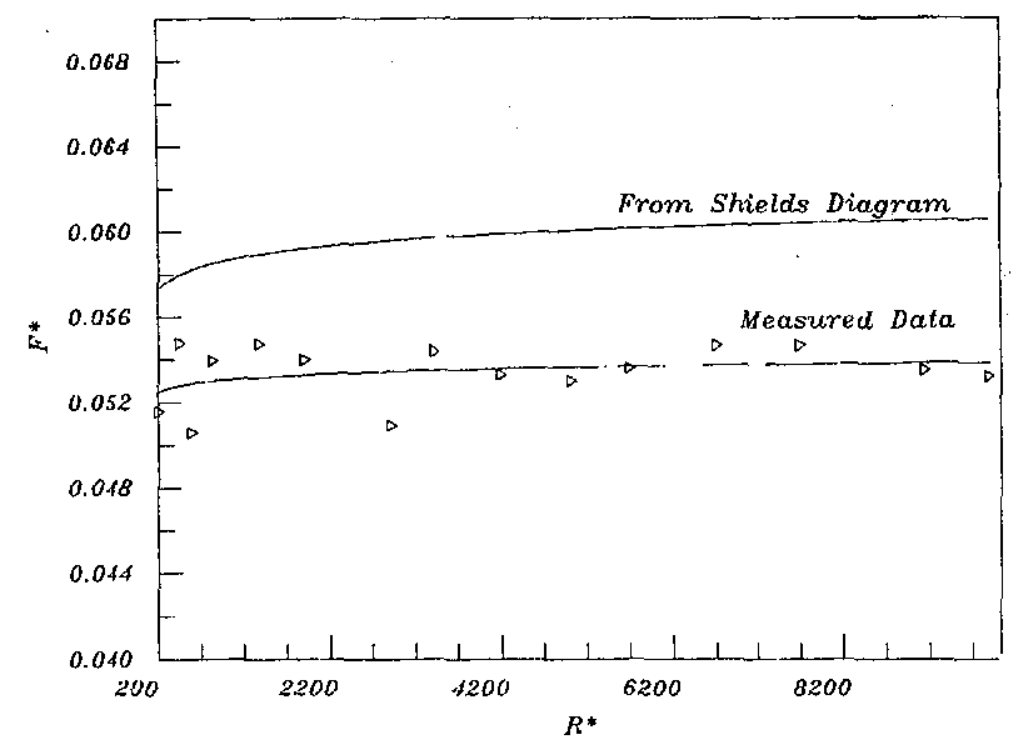

Fig.(1) Comparison between the dimensionless critical shear stress and the boundary Reynolds number

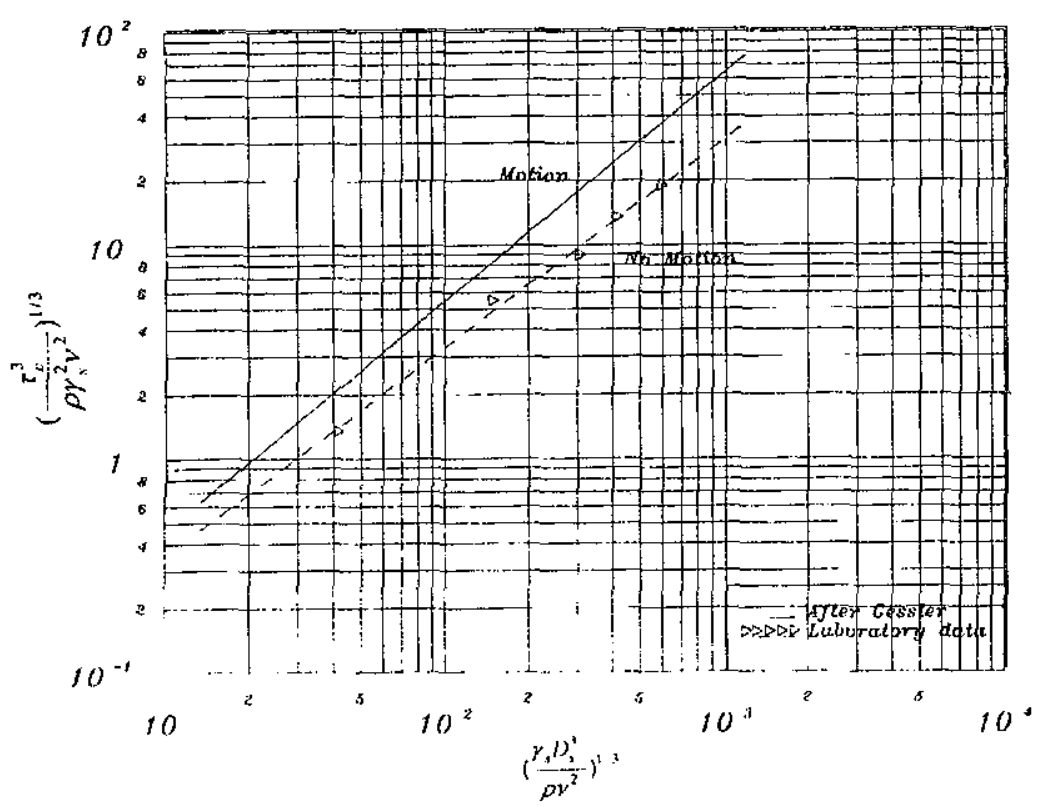

Figl(2) romparison between initiation of motion after Gessler wodification. (1971) atd the cxperimental results 


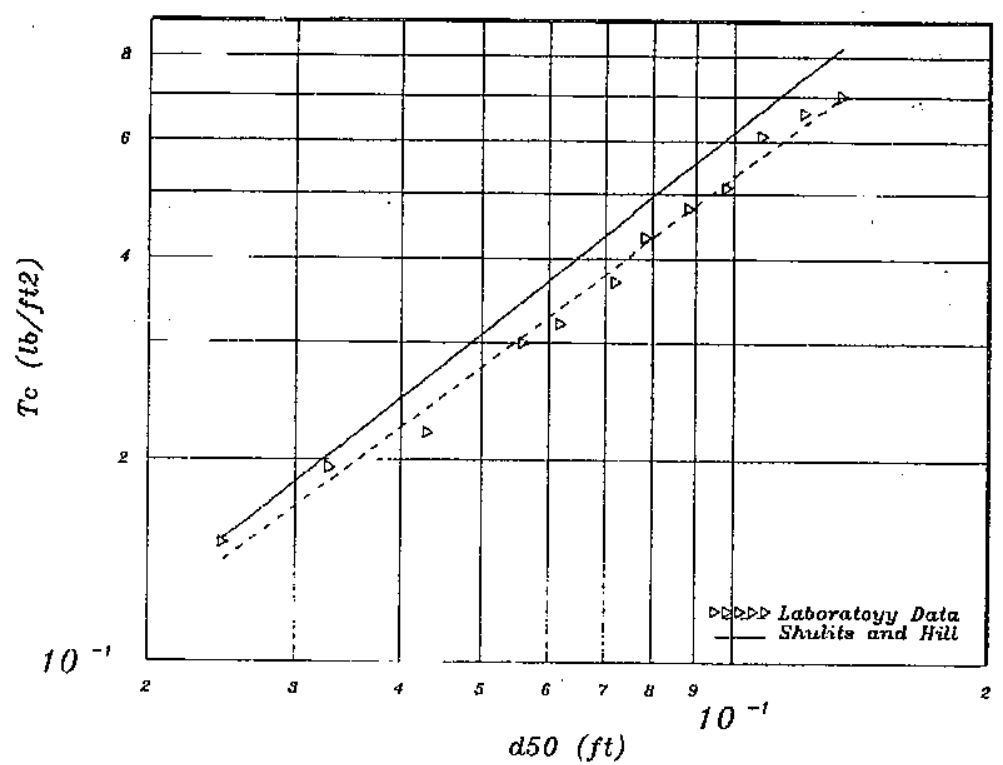

Fig.(3) Comparison between critical shear stress according to Shalits and Hill, 1968 and the Laboratory results

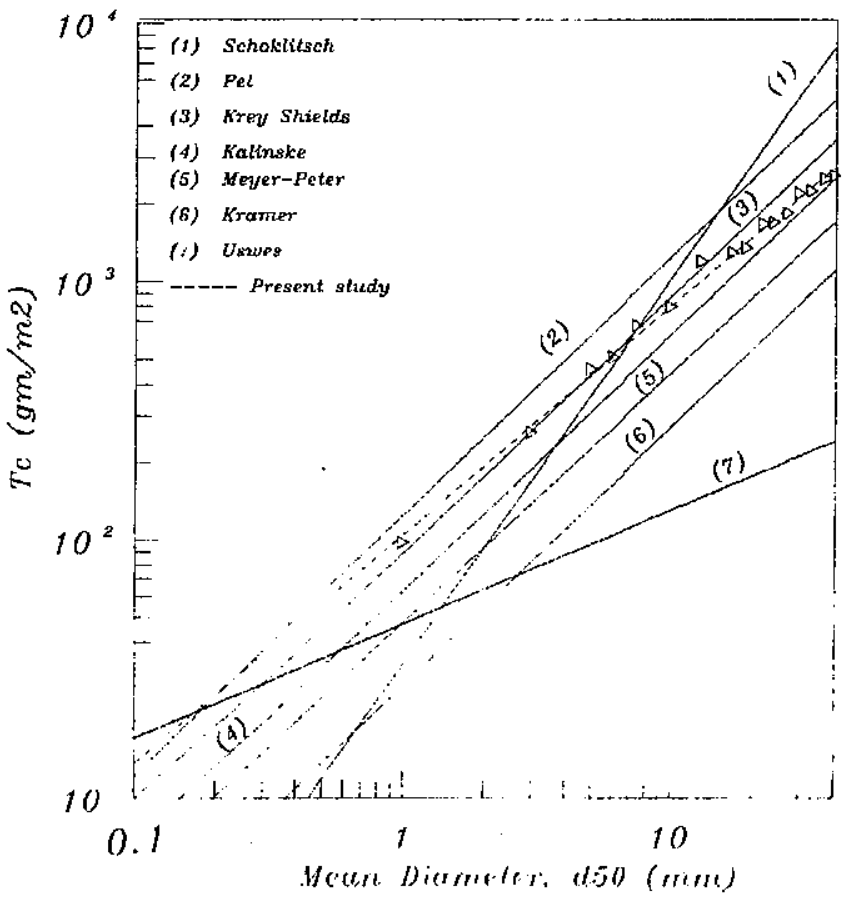

Fig.(t) (ritiral shear stress as a function of grain diameter: (a comparison between line laburatory insirlts and the arralylical results, after Chien, 195.) 


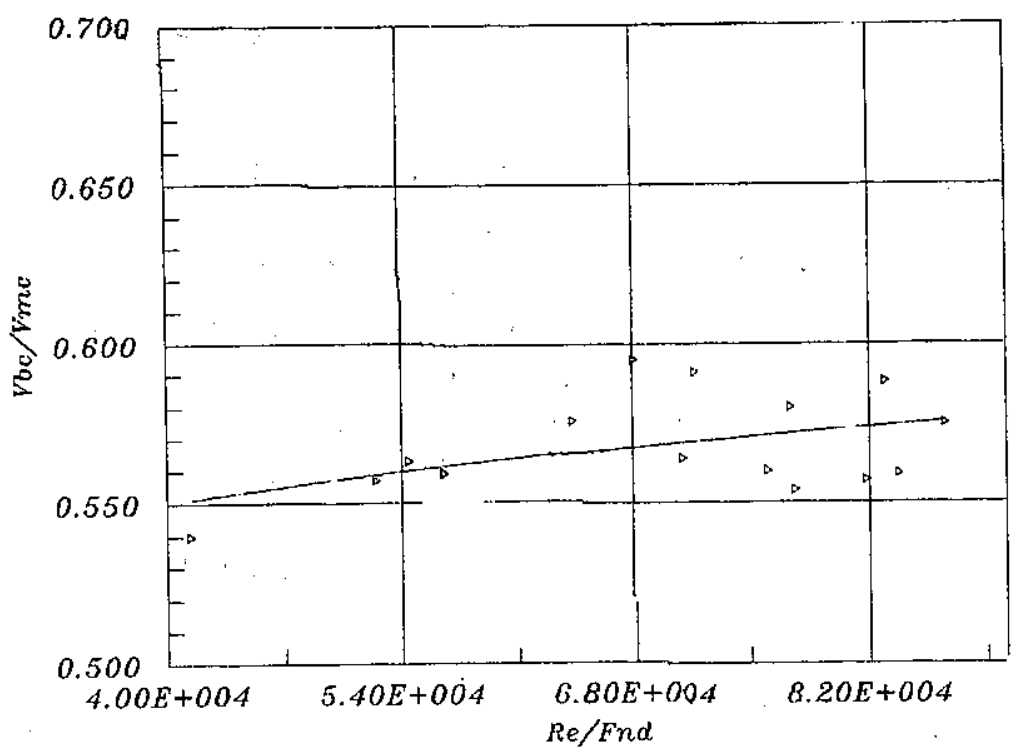

Fig.(5) Variation of dimensionless critical bed velocity versus (Re/Fnd)

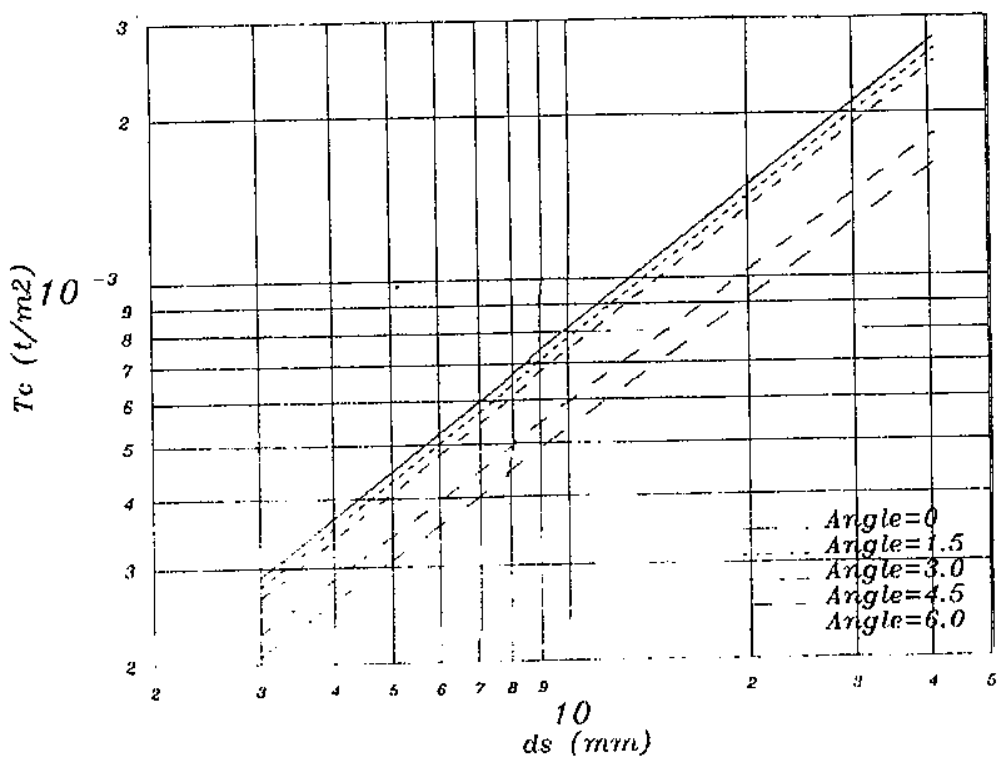

Fig.(b) Infuterre of the dowsunard bed angle on the criticat shear stress required to intilicale molion 


\section{دراسة ابتداء مركة جزينات القاع للتنوات ذات التطاع الزلطى}

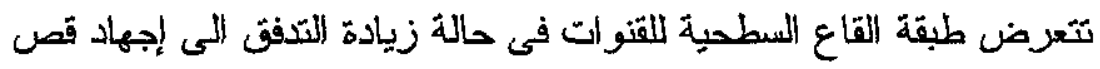

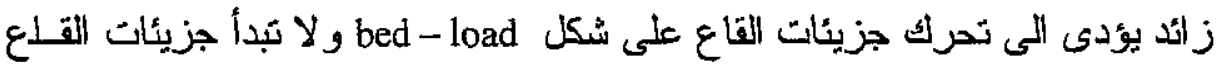

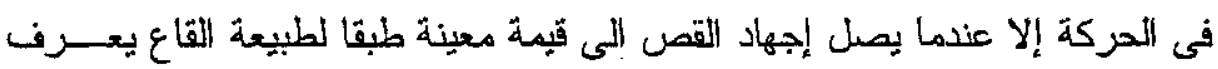

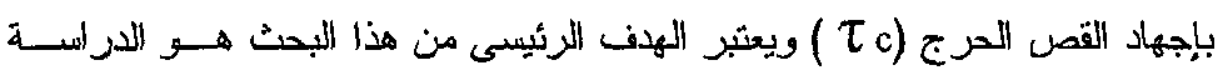

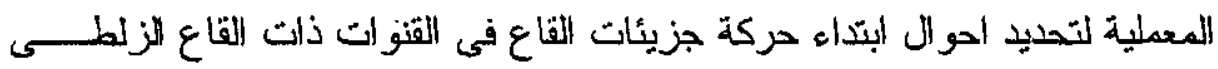

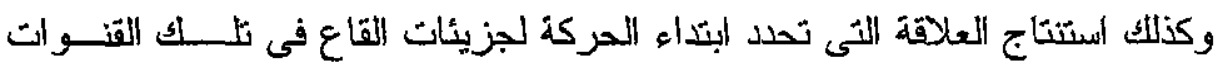
ومقارنة نتائج تلك العلاقة بالعلقات الموجودة تحت نفس الظزوف كما تـم قيـاس

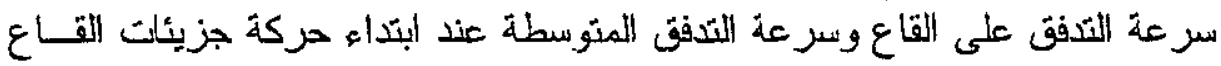

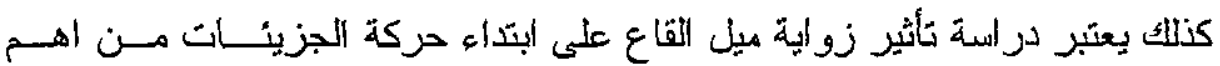

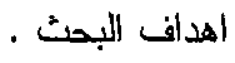

ومن هذه الدر اسة المعلية تم استتناج العلاقة التى تحدد اجهاد القص الحرج

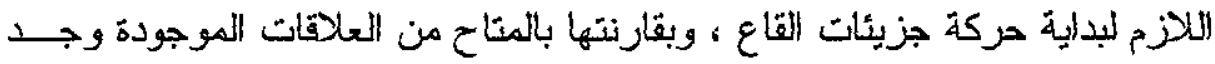
أن النتائج المعملية اقرب ما نكون الى نتائج

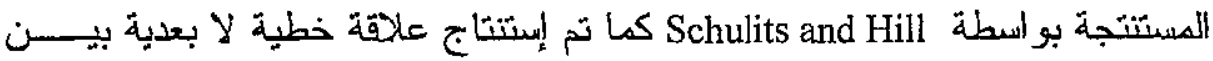

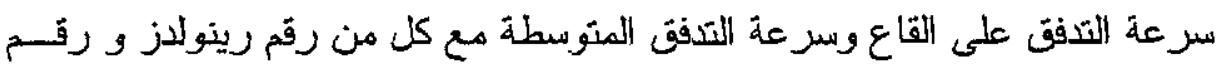

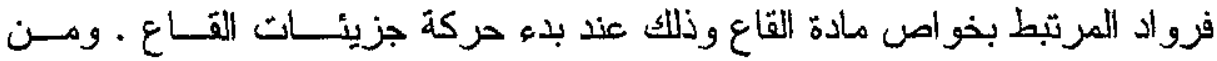

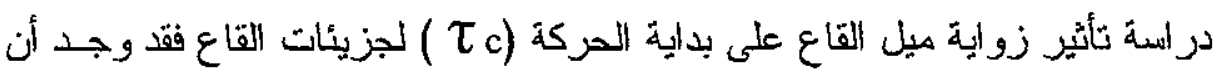
هناك علاقة عكسية بين اجهاد القص الحرج (cos $\theta$ ( 